To the best of our knowledge there are no measures of 'psychodynamic origin' specifically related to avoidant personality disorder and hence we used the PDBQ. Furthermore, it was not feasible to keep the independent assessors who completed the SCID-II unaware of the treatment group in a number of instances.

Post-treatment CBT was significantly superior to BDT on all 'primary' outcome measures. A significance level of $\alpha=0.1$ set rather than 0.01 as claimed by Leichsenring $\&$ Leibing. Even if we exclude the SPAI scores $(P=0.09)$, this still leaves superior outcome for CBT on three out of four outcome variables. The lack of power to detect differences between the waiting-list control group and the active treatments is acknowledged as a limitation.

There are important differences between our study and that of Svartberg et al (2004). Svartberg et al included all types of cluster $\mathrm{C}$ and self-defeating personality disorders, rather than limiting their study to avoidant personality disorder. Twofifths of their sample did not fulfil criteria for avoidant personality disorder treatment and treatment consisted of 40 rather than of 20 sessions. Furthermore, outcome with respect to personality disorders (sic) was only assessed with the Millon Clinical Multiaxial Inventory (Millon, 1994), rather than with the gold standard SCID-II. Finally, the lack of a control group in the study of Svartberg et al renders the results difficult to interpret.

In contrast to most other psychotherapy studies, we did our utmost to prevent an effect of investigator allegiance. The study was designed in close cooperation with two psychodynamic therapists (G.F. and H.K.) and two cognitive-behavioural therapists (A.B. and A.K.), who all fully participated in the design of the study, selection of measures, treatment manuals (including degree of flexibility) and therapists.

Emmelkamp, P. M. G., Grauwelman, I. \& Rengers, L. (2004) Onderzoek naar cognitieve gedragstherapie en psychodynamische therapie bij de ontwijkende persoonlijkheidsstoornis: De construct validiteit van de behandelingen. [Research into CBT and BDT of the avoidant personality disorder: the construct validity of the treatments] In Psychoanalytische Psychotherapie Vergelijkenderwijs (eds W. B. C. Hoenink, M. J. Rexwinkel \& W. Roelofsen), pp. 37-45. van Gorcum.

Millon, T. (1994) Millon Clinical Multiaxial Inventory-III. Dicandrien.

Samoilov, A., Goldfried, M. R. \& Shapiro, D. A. (2000) Coding system of therapeutic focus on action and insight. Journal of Consulting and Clinical Psychology, 68, 513-514.

P. M. G. Emmelkamp Department of Clinical Psychology, University of Amsterdam, Roetersstraat 15, I0I8 WB Amsterdam, The Netherlands. Email: P.M.G.Emmelkamp@uva.nl

doi: 10.1192/bjp.190.1.80a

\section{Anti-phospholipid antibodies, neuroleptic treatment and cardiovascular morbidity}

Joukamaa et al (2006) reported a clear relationship between the number of neuroleptic drugs prescribed and mortality of people with schizophrenia. The more important causes of death were cardiovascular disease and unspecified respiratory disease. Moreover, the authors postulated that overlooked venous thrombosis or pulmonary embolism accounted for some respiratory deaths.

Oomen et al (1995) documented increased vascular morbidity at 2 -year follow-up in patients with anti-phospholipid antibodies who were newly admitted for psychiatric treatment. These patients showed a range of cardiovascular accidents (arterial or venous thrombosis, pulmonary embolism and myocardial infarction). The negative control group without anti-phospholipid antibodies had no vascular complications during follow-up.

Vascular events associated with such autoantibodies range from superficial to life-threatening multiple organ thrombosis developing over a short period ('catastrophic' anti-phospholipid syndrome). Thrombosis in anti-phospholipid syndrome appears to be a 'two-hit' phenomenon. Autoantibodies (the first 'hit') are continually present in the circulation, yet a local trigger (the second 'hit') is required to induce thrombus formation. Erkan \& Lockshin (2006) recently suggested the elimination of reversible thrombosis risk factors and heparin prophylaxis during high-risk periods in people with persistent anti-phospholipid antibodies. Chengappa et al (1991) and Schwartz et al (1998) demonstrated a high prevalence of anti-phospholipid antibodies (about 30\%) in patients. A prospective study is ongoing in our departments to confirm the prevalence of anti-phospholipid antibodies with a first episode of acute psychosis before and after neuroleptic treatment. If historical data are confirmed, more attention should be paid to the fact that up to one-third of patients presenting with psychosis have anti-phospholipid antibodies and are at risk of cardiovascular or respiratory morbidity/ mortality when neuroleptic treatment or physical restraint are used.

Chengappa, K. N., Carpenter, A. B., Keshavan, M. S. et al (1991) Elevated IGG and IGM anticardiolipin antibodies in a subgroup of medicated and unmedicated shizophrenic patients. Biological Psychiatry, 30, 73I-735.

Erkan, D. \& Lockshin, M. D. (2006) Antiphospholipid syndrome. Current Opinion in Rheumatology, 18, 242-248.

Joukamaa, M., Heliövaara, M., Knekt, P., et al (2006) Schizophrenia, neuroleptic medication and mortality. British Journal of Psychiatry, 188, 122-127.

Oomen, H. A., Wekking, F. M., de Jong, J., et al (1995) Screening psychiatric admissions for anticardiolipin antibody. Psychiatry Research, 58, 83-88.

Schwartz, M. D., Rochas, M., Weller, B. et al (1998)

High association of anticardiolipin antibodies with psychosis. Journal of Clinical Psychiatry, 59, 20-23.

E. Leuci Psychiatry Department, Parma, Fidenza, Italy.

L. Manenti Psychiatry Department, Fidenza District, ASL Parma, Via Berenini I5I, Fidenza (PR), 43100 Italy. Email: lucio.manenti@aod.it

C. Maggini Psychiatry Department, Parma, Fidenza, Italy.

doi: 10.II92/bjp.190.I.8I

\section{Letters to the Editor}

In order to speed up the publication of correspondence and to encourage debate among our readers and authors, all letters to the Editor must from now on be submitted online as eLetters. Hard-copy submissions will no longer be considered. To submit an eLetter, click 'submit a response' in the box at the top right of the screen when viewing online an article on which you wish to comment. If your letter is a general one, and not in response to a specific article, please 'submit a response' to this letter (you can also submit a general letter from the eLetters home page). We aim to publish eLetters online, if accepted, within 10 days of submission. A selection of these letters will be included in subsequent printed issues.

\section{Correspondence Editors}

doi: 10.1192/bjp.190.1.8la 